\title{
A AMÉRICA LATINA NOS MODELOS GEOPOLÍTICOS MODERNOS: da marginalização à preocupação com sua autonomia
}

\author{
Heriberto Cairo*
}

\begin{abstract}
Este artigo procura entender as transformações nas formas de inserção da América Latina no contexto de eras geopolíticas, buscando explicitar suas causas e, sobretudo, suas conseqüências, no contexto da nova geopolítica contemporânea, em que a região se desloca de uma posição marginal ou passiva para assumir contornos próprios de autonomia, às vezes marcados como zonas de perigo. A análise ultrapassa a simples posição da região na geopolítica Ocidental e baseia-se num exercício de uma geopolítica do conhecimento. Para tanto, o autor resgata as principais contribuições da literatura sobre processos de continuidade de ordens geopolíticas permeadas de mutações, identificando as sucessivas eras geopolíticas de John Agnew que, grosso modo, se correlacionam com as ordens geopolíticas existentes: a geopolítica naturalizadora, do início do século XX; a era pós Segunda Guerra Mundial, da geopolítica ideológica; e a formação de uma nova era geopolítica com o fim da Guerra Fria.

PALAVRAS-CHAVE: América Latina, geopolítica moderna, geopolítica do conhecimento, representação do espaço, hegemonia.
\end{abstract}

\section{INTRODUÇÃO}

A existência de uma ordem geopolítica internacional tem implicado certa continuidade nas estruturas e discursos geopolíticos, durante determinados períodos, separados por transições geopolíticas. A literatura geopolítica recente relativa à questão da continuidade nos oferece duas alternativas: a das ordens geopolíticas mundiais de Peter J. Taylor e Colin Flint (2000); e as ordens geopolíticas conectadas a eras geopolíticas específicas, de John Agnew e Stuart Corbridge (1995).

Mesmo reconhecendo que os códigos geopolíticos de cada país guardam certa independência uns dos outros, Taylor e Flint, consideram que os atores mais relevantes no contexto internacional conseguem impor a todos uma única pauta geral: as ordens geopolíticas mundiais. A existência de uma ordem geopolítica mundial, segundo esses autores, portanto, só se estrutura com a pre-

* Professor Titular de Ciência Política e de Administração na Faculdade de Ciência Política e Sociologia da Universidad Complutense de Madrid.

Campus de Somosaguas, 28223. Madrid - España. hcairoca@cps.ucm.es sença de uma potência dominante. Agnew e Corbridge (1995), no entanto, interpretam as ordens geopolíticas de maneira distinta. Para eles, essas ordens são constituídas pelo conjunto de regras, instituições, atividades e estratégias que se convertem em rotinas em cada período histórico, assumindo características geográficas determinadas. Essas ordens geopolíticas são sustentadas por relações de poder coercitivas ou consensuais, mas não supõem necessariamente a existência de uma potência dominante, já que, em boa medida, as práticas materiais e representações hegemônicas estabelecem sentidos comuns. Nesse sentido, a perspectiva de Agnew e Corbridge tem inspiração gramsciana. As ordens constituem um modo de representação hegemônico, inspirado ou não numa potência hegemônica, não necessariamente imposta pela força. Assim, eles distinguem três ordens geopolíticas desde o século XIX: a ordem geopolítica britânica do Pacto da Europa (1815-1875); a ordem geopolítica da rivalidade inter-imperial (1875-1945); e a ordem geopolítica da Guerra Fria (1945-1990). Atualmente, estaríamos entrando em uma nova ordem geopolítica, que poderíamos denominar de 
ordem da globalização militarizada, por falta de consenso sobre a questão, a qual se traduz por um discurso homogeneizador da geopolítica, cujo conteúdo seria estender as formas econômicas de mercado de acesso livre e as formas políticas de democracia representativa a todo o planeta.

Nessas ordens geopolíticas, a política mundial foi organizada em torno de caracterizações do espaço definidas por sucessivos discursos geopolíticos que formulam, ao mesmo tempo, modos de representação dos espaços. São as eras geopolíticas, segundo a definição de John Agnew (2003). Elas correspondem, grosso modo, aos três períodos das ordens geopolíticas: a geopolítica civilizacional, a geopolítica naturalista e a geopolítica ideológica. Essas periodicidades não são absolutamente exatas. Existem continuidades entre elas, mas, em cada período, diferentes princípios se inter-relacionam de diversas maneiras, produzindo uma combinação distinta de representações e práticas geopolíticas, e, nesse caso, também, as eras geopolíticas estão associadas aos períodos hegemônicos, ainda que não coincidam exatamente com eles. Segundo Agnew,

a imaginação geopolítica dominante, que retrocedeu nesses períodos, teria antigas raízes no crescimento do capitalismo e da formação dos Estados na Europa, no início da era moderna e na expansão européia sobre o resto do mundo. As hegemonias que caracterizariam as diferentes eras não estão livres de contradições nem de crítica. De fato, partindo de suas contradições internas é que as velhas hegemonias são subvertidas, e surgem as novas (2003, [2005, p.103]).

Na conformação da imaginação geopolítica de cada era, as universidades e os institutos de pesquisa desempenham um papel fundamental. É a geopolítica teórica que, junto à geopolítica prática dos intelectuais do Estado, como diplomatas e militares, conformam a visão geopolítica de cada Estado. Os modelos geopolíticos não só proporcionam uma representação do espaço perfeitamente ordenada, mas também são um lócus de enunciação muito mais poderoso que o de outras representações do espaço. Os modelos são científicos, ou seja, são considerados verdadeiros e neutros - ignorando-se, freqüentemente, seu caráter interessado -, diferentemente do conhecimento formulado por diplomatas e militares que, obviamente, respondem a uma determinada visão do Estado.

Ocuparemo-nos agora da América Latina nos modelos geopolíticos modernos, o que supõe situar nossas indagações no início do século XX, com o primeiro modelo geopolítico formal formulado pelo inglês Halford T. Mackinder, para, em seguida, transitar pela era geopolítica da Guerra Fria e, finalmente, analisar os modelos posteriores ao final da Guerra Fria, que oferecem novas formas de pensar a América Latina no mundo. Não se trata apenas de caracterizar a América Latina na tradição geopolítica ocidental, mas de fazer um exercício de geopolítica do conhecimento como tão magistralmente o fizeram recentemente autores como Walter Mignolo (2005) ou David Slater (2004) sobre essa região.

\section{REGIÃO MARGINAL NA GEOPOLÍTICA NATU- RALISTA}

Na era da geopolítica naturalista, que coincide, grosso modo, com a ordem geopolítica da rivalidade inter-imperial, vão se desenhar modelos geopolíticos cuja principal característica

foi enfatizar o caráter determinante da localização geográfica ou das condições ambientais. O relativo êxito de certos Estados na competicãa internacional era atribuído às vantagens absolutas que sua localização lhes proporcionava e a algumas condições meio ambientais superiores" (Agnew, 2003, [2005, p.119]). ${ }^{1}$

Um Estado estaria condenado, por exemplo, à falta de estabilidade, caso se encontrasse em uma localização maldita, enquanto poderia gozar de certa tranqüilidade em outras latitudes. A explicação do comportamento dos Estados, nesse tipo de geopolítica, respondia a uma metafísica do solo, do território: acompanhavam forças telúricas das quais, em termos gerais, não poderiam escapar.

Não faremos uma análise exaustiva de to-

Isto é o que poderíamos considerar como o pecado original da Geopolítica como disciplina, já que, muitas vezes, acaba sendo associada a essa forma particular de abordar a análise das práticas espaciais dos Estados e de suas representações. 
dos os modelos elaborados. Ocuparemo-nos do primeiro e mais importante, o de Mackinder, do de Nicholas J. Spykman, que o segue, e de outro modelo, de certa forma alternativo, o de Karl Haushofer.

\section{O caráter crucial da obra de Mackinder}

A obra de Mackinder foi de importância capital no surgimento da Geopolítica, ${ }^{2}$ ou seja, foi Mackinder quem conformou essa subdisciplina tal como hoje a conhecemos; e foi ele precisamente quem encaixou as diversas peças do conjunto.

Não é por acaso que a obra de Mackinder se desenvolve em plena época de expansão imperial britânica, momento que deu lugar a um crescente interesse pelos problemas de ultramar. Sua preocupação com vantagens geoestratégicas da potência terrestre sobre a potência marítima, para o domínio do planeta, refletia, em grande medida, um fato: a repartição colonial dos territórios livres ultramarinos havia se completado, e diversas potências começavam a exigir novas divisões, inconformadas com as injustiças da repartição anterior, quando não passavam diretamente à ação, desalojando velhos impérios de seus domínios coloniais - sem ir mais longe, veja-se a agressão norte-americana aos restos do império espanhol em 1898 -, para apoderar deles. O próprio Mackinder afirmava que o início do século XX marcaria o fim da época colombina, durante a qual a exploração geográfica do planeta praticamente se completou, e, o que era ainda mais importante, já não existiam territórios cuja possessão se pudesse realizar de forma pacífica. Por isso considerava que "daqui em diante, na era pós-colombina, encontraremos um sistema político fechado e, o que não é menos importante, a sua esfera de ação será o mundo inteiro. Todas as explosões das forças sociais que se produzam em vez de dissipar-se num âmbito circunvizinho de espaço desconhecido, no

${ }^{2}$ Estamos de acordo com Parker de que ele foi "quem uniu estes diferentes fragmentos de pensamento para produzir o que L.S. Amery chamou "uma idéia compreensiva”" (1985, p.16). qual dominam a barbárie e o caos, serão diretamente refletidas nos mais distantes cantos do globo e, por esta razão, os elementos frágeis do organismo político e econômico do mundo serão destroçados." (Mackinder, 1904 [1975, p.66]). ${ }^{3}$

Em tais circunstâncias, e a partir dessa percepção, Mackinder elaborou seu conhecido modelo (Figura 1), apresentado primeiramente no artigo The geographical pivot of history, publicado em 1904, na revista Geographical Review, e desenvolvido extensamente num livro posterior, publicado em 1919, Democratic Ideals and Reality. Com base na interpretação da história européia, Mackinder considerava que o Estado que ocupasse o coração continental (Heartland) - ou a região pivô (Pivot Area), segundo a versão de 1904 -, dentro da Eurásia, poderia exercer uma influência decisiva sobre a vida política do mundo inteiro. A fim de opor essa superioridade geoestratégica, Mackinder prescrevia à potência marítima - naquele momento, o Reino Unido - uma política de equilíbrio de poder no cinturão interior (Inner Crescent), a periferia da Eurásia, que contorna o coração continental, já que, se essa massa fosse dominada pela potência terrestre, inevitavelmente essa última dominaria a ilha mundial (World-Island), ou seja, o conjunto terrestre da Eurásia e África, e, em última instância, o mundo. Essa idéia está claramente explícita em sua conhecida fórmula:

Quem governe a Europa Oriental dominará o Coração Continental;

quem governe o Coração Continental dominará a Ilha Mundial;

quem governe a Ilha Mundial dominará o mundo (Mackinder, 1919, p.106).

O cinturão exterior (Outer Crescent), as ilhas e continentes situados para além da Eurásia, seriam o âmbito espacial "natural" da potência marítima. ${ }^{4}$ Aqui encontramos a América Latina nesse

${ }^{3}$ Mackinder insiste especialmente no caráter interconectivo do sistema, até estabelecê-lo quase em termos de unidade organicista. Pode-se deduzir das afirmações de Mackinder que compreende de forma bastante precisa o mecanismo fundamental do imperialismo: exportar os conflitos sociais no seio da nação a uma escala internacional.

${ }^{4}$ Uma formulação deste tipo se presta facilmente à crítica pelo seu determinismo; é fácil deduzir da obra de Mackinder que, para ele, os processos geopolíticos rele- 


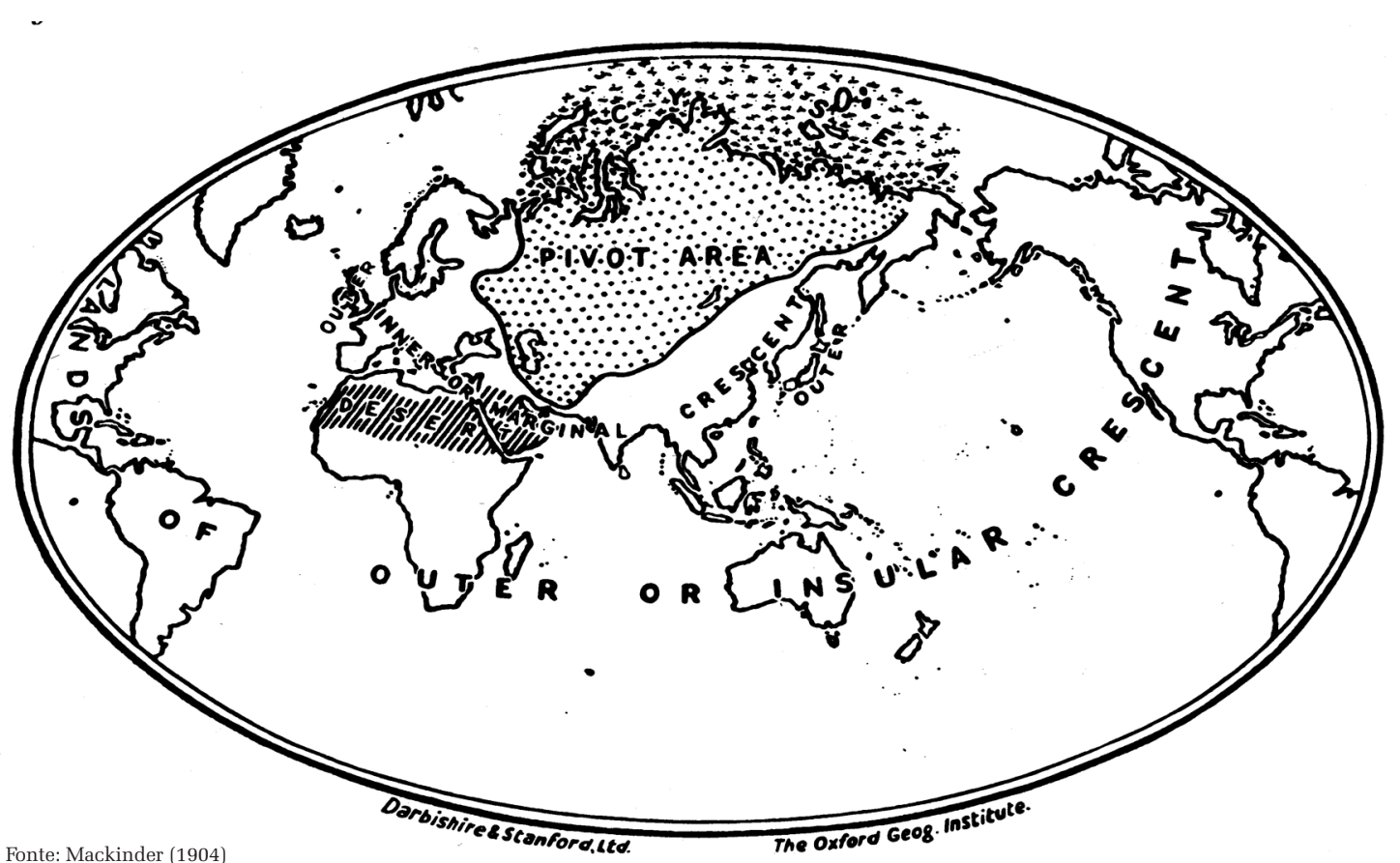

modelo, que estaria situada no âmbito de influência do Reino Unido nessa época.

Se julgarmos pela extensão que a região ocupa em seus escritos, para Mackinder, ela era, inclusive, de menor importância que a África subsariana. Por exemplo, no texto de 1919, ele lhe dedica escassos comentários, quase sempre ligados, ademais, a reflexões sobre os Estados Unidos. ${ }^{5} \mathrm{De}$ sua perspectiva, é plenamente lógico centrar-se no continente euro-asiático, porque aí é onde se decide o futuro do mundo. Nesse marco, a América Latina seria uma dessas regiões do globo que se dá por suposto, ou seja, que está dentro dos domínios da potência marítima, distanciada das zonas de conflito principal, mas também do centro do mundo.

No entanto, Mackinder não descarta a futura importância da região:

vantes são determinados pela posição que as diferentes potências ocupam no planeta. De fato, essa concepção lembra muito a interpretação que Ratzel fazia do evolucionismo darwinista, e que poucos estariam dispostos ainda a defender na atualidade. No entanto, as fórmulas de ação prescritas por Mackinder não se adéquam a esse tipo de fatalismo já que, como afirma $\mathrm{G}$ Parker, "pressupunham um alto grau de potencial emancipável daquelas ataduras ambientais que tanto se haviam apertado historicamente" (1985, p.27).

Reflexões que não chegam nem a uma página das 148 que tem a edição trabalhada.
O desenvolvimento das grandes potencialidades da América do Sul pode ter uma influência decisiva para o sistema. Podem fortalecer os Estados Unidos ou, pelo contrário, se a Alemanha pudesse desafiar com êxito a doutrina Monroe, poderia separar Berlim do que talvez possa descrever como uma política de pivô (1904 [1975, p.80]).

Mas essa reflexão tampouco muda muito a representação mackinderiana da América Latina, e é importante destacar que, para ele, ainda que sua influência pudesse chegar a ser decisiva, apenas desempenharia um papel subordinado à potência hegemônica européia ou norte-americana (seja essa qual fosse).

\section{Spykman: o teórico da transição da potência marítima}

Nicholas J. Spykman foi um norte-americano de origem holandesa, que, ao final dos anos de 1930, se aprofundou na análise das relações entre geografia e política exterior (p. exe. 1938a; 1938b), expressando, de novo, a fórmula que, desde Napoleão, fascina a todo homem de Estado realista: "A Geografia é o fator condicionante mais fun- 
damental na formulação de uma política [exterior] nacional porque é o mais permanente" (Spykman, 1938a, p. 29).

Spykman é conhecido especialmente por seus dois livros (1942; 1944), escritos com a intenção explícita de intervir na formação da política exterior norte-americana. Neles, partindo da consideração de que

a sociedade internacional é [...] uma sociedade sem uma autoridade central para manter a lei e a ordem e sem uma instância oficial que proteja seus membros no uso de seus direitos [...] [Spykman estabelece que] uma acertada política exterior para os Estados Unidos [...] deve desenvolver uma 'estratégia global' (grand strategy), tanto para a guerra como para a paz, baseada nas implicações de sua localização geográfica no mundo (1942, p.7-8).

Tendo como base o modelo de Mackinder, Spykman minimiza o interesse no controle do $\mathrm{Co}^{-}$ ração continental. Para ele o anel continental (Rimland) é a área chave - que corresponde, grosso modo, ao cinturão interior de Mackinder -, cujo controle permitiria um domínio global do planeta (Figura 2). Uma tarefa da potência marítima seria, portanto, o controle de um anel continental euroasiático unificado. A potência marítima, nas proximidades da Segunda Guerra Mundial, já não era mais a Grã-Bretanha. Assim, quando Spykman (1944) defendia a intervenção dos Estados Unidos nas terras periféricas da Eurásia, ele está afirmando claramente que se produziu uma transição geopolítica - ou se está produzindo.

E que ocorre com a América Latina, no modelo de Spykman? A região não está nesse anel continental, e, portanto, não é peça fundamental da estratégia de domínio global do autor. Isso se reflete na escassa atenção que Spykman presta à América Latina.

Essa posição é paradoxal, já que seria de se esperar que, em um modelo geopolítico no qual os Estados Unidos ocupam um lugar central, a região terrestre adjacente tivesse um maior protagonismo. Mas, de fato, quando Spykman faz alusão ao $\mathrm{He}$ misfério Ocidental, que as Américas ocupam, trata quase exclusivamente dos problemas, necessidades e objetivos dos Estados Unidos. E isso não é estranho, já que, para Spykman, "o autêntico centro de poder no Hemisfério Ocidental está na costa atlântica da América do Norte.” (1944, p.24).

Essa combinação de territórios tão diversos como o continente americano (o Hemisfério Ocidental de Spykman), nucleado pela região mais desenvolvida, não será alheia a outro modelo geopolítico, que, curiosamente, também se autodenominava "mackinderiano", ainda que rompesse com algumas de suas premissas, e que foi proposto pela Geopolitik alemã, o modelo das pan-regiões.

Figura 2 - O mundo segundo Spykman (1944)

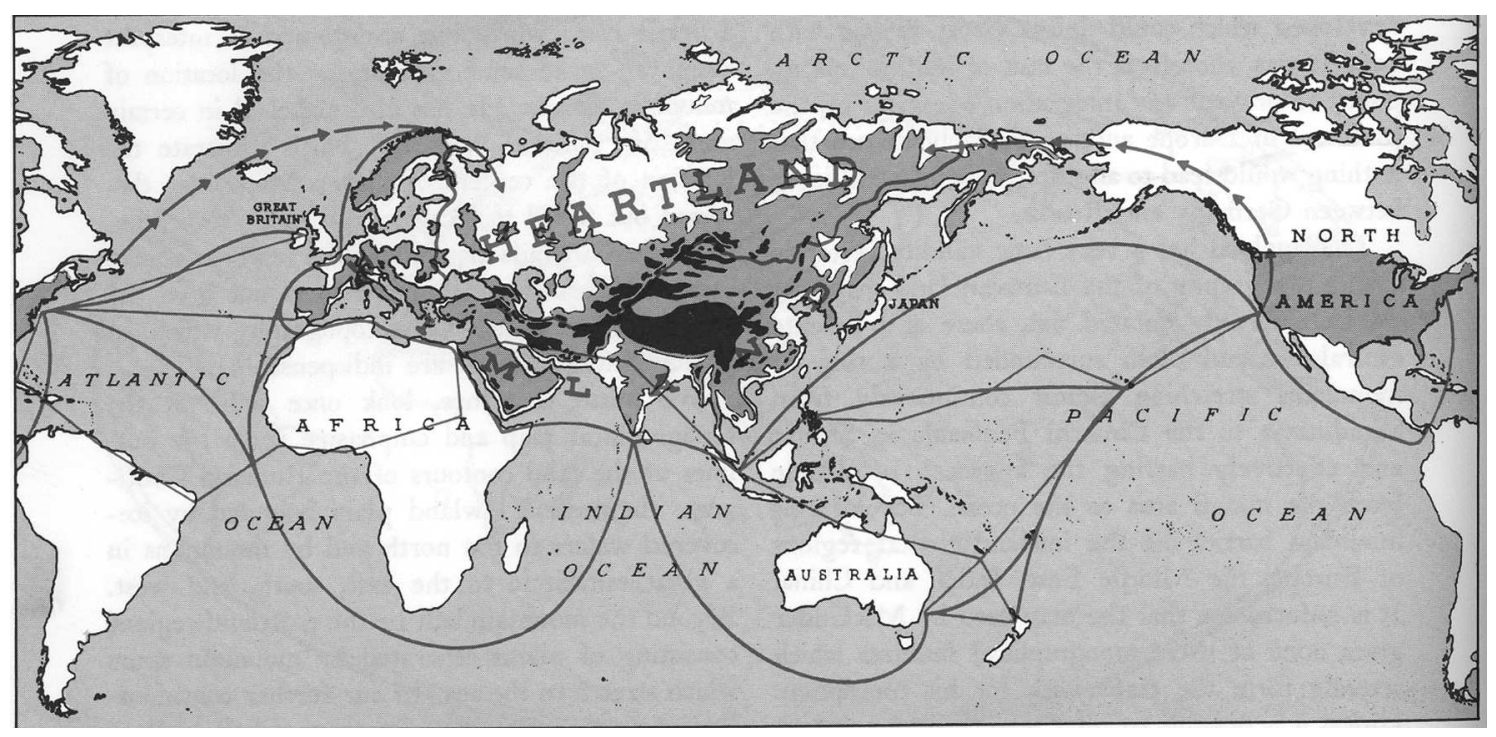

Fonte: Spykman (1944, p.38) 
O modelo geopolítico nacional-socialista das pan-regióes

Ainda que possa parecer inovadora, a idéia de constituir grandes espaços integrados, para potencializar os benefícios das diversas partes, não é nova. Nos anos 1930, os geopolíticos nazi-alemães formalizaram esquemas de integração NorteSul, onde combinavam povos imperiais e povos colonizados. Embora a formulação, como veremos, fosse nova, ela também constituía um exemplo extremo da presunção, comum na época, de que "o mundo estava constituído por agrupamentos raciais que podiam ser nitidamente divididos em dois 'tipos' de povos, e uns existiam fundamentalmente para servir aos outros" (Agnew; Corbridge, 1995, p.59).

A racionalidade político-econômica de tais agrupamentos se sustentava no conceito de Lebensraum (espaço vital). A idéia preponderante era que os povos mais avançados - as economias mais industrializadas dos Estados Unidos, Alemanha e Japão - necessitavam espaço suficiente para abastecerem-se de matérias primas, sem desprezar o papel que desempenhariam como mercados para seus produtos manufaturados. O objetivo era conseguir a autarquia da unidade política. No plano de distribuição de tarefas das ciências políticas delineado por Kjellen (1916 [1917]), se a Geopolitik deve determinar a área natural do Estado - já que essa seria sua melhor forma de vida -, do mesmo modo a Oekopolitik deve esforçar-se em mostrar as vias para alcançar a autarquia - que seria a melhor forma de vida do Estado no terreno econômico. Lebensraum e autarquia estavam, então, estreitamente associados. O resultado é que as necessidades do Estado, e, em particular, do Estado alemão, deviam ser satisfeitas por outras regiões, incorporadas em grandes espaços, organizados em torno ao centro alemão e outros centros industriais no Norte, então concebidos como pan-regiões.

Um terceiro elemento nesse esquema era as "pan-idéias" (Panideen), concebidas como um princípio ideológico fundamental sobre o qual os Estados poderosos desenvolviam sua política. Era uma forma especial de Raumsinn, de sentido do espaço. Se considerarmos, como já foi afirmado por O'Loughlin e Van der Wusten (1990, p.2) e Saxe Fernández (1991, p.27), que Haushofer (1931) e seus seguidores admiravam o modelo estadunidense de consolidação de um império formal e informal a partir da pan-idéia do destino manifesto, podemos entender que, por trás de cada pan-região, existe uma pan-idéia.

As pan-idéias eram conceitos fundamentalmente culturais, mas os geopolíticos nazis não deixaram de incorporar aspectos econômicos à noção de pan-região. Assim, as idéias desenvolvidas por Alfred Weber (1929) acerca das áreas econômicas ampliadas (Grosswirtschaftsraum) completavam esse quadro à perfeição. Como afirma Saxe Fernández:

Para o líder alemão era indispensável a proposicão de que a era do Estado Nacional como unidade econômica devia ser substituída pela idéia de grandes áreas (Grossraume) que apresentaram certa unidade geográfica e econômica (1991, p.26).

E acrescenta-e é importante reter isso, pois é uma das chaves no paralelismo atual que tentamos estabelecer: "há que enfatizar que com isto não questionavam de nenhuma maneira a funcionalidade do estado alemão, mas a de seus vizinhos" (p.26).

Os primeiros desenhos de pan-regiões que Haushofer e associados (Figura 3) produziram, definiam três ou quatro grandes espaços: Pan-Europa-que, às vezes, se formula como Pan-Euráfrica -, com centro na Alemanha e nas zonas industriais adjacentes, incorporando explicitamente a África em alguns momentos, mas, em outros, mantendoa como região separada, mas subordinada; PanÁsia, com centro no Japão; Pan-América, com centro na região nordeste dos Estados Unidos; finalmente, também, em alguns desenhos, aparecia a Pan-Rússia, com centro em Moscou. ${ }^{6}$

${ }^{6}$ A presença ou não da Pan-Rússia pode estar relacionada às idas e vindas das relações da Alemanha hitleriana com a União Soviética: se, no desenho da Figura 3, a PanRússia não está presente, quando os exércitos hitlerianos invadem a URSS, a Pan-Rússia desaparece - literalmente - do mapa, sendo a maior parte de seus territórios incorporada à pan-região dominada pela Alemanha. 


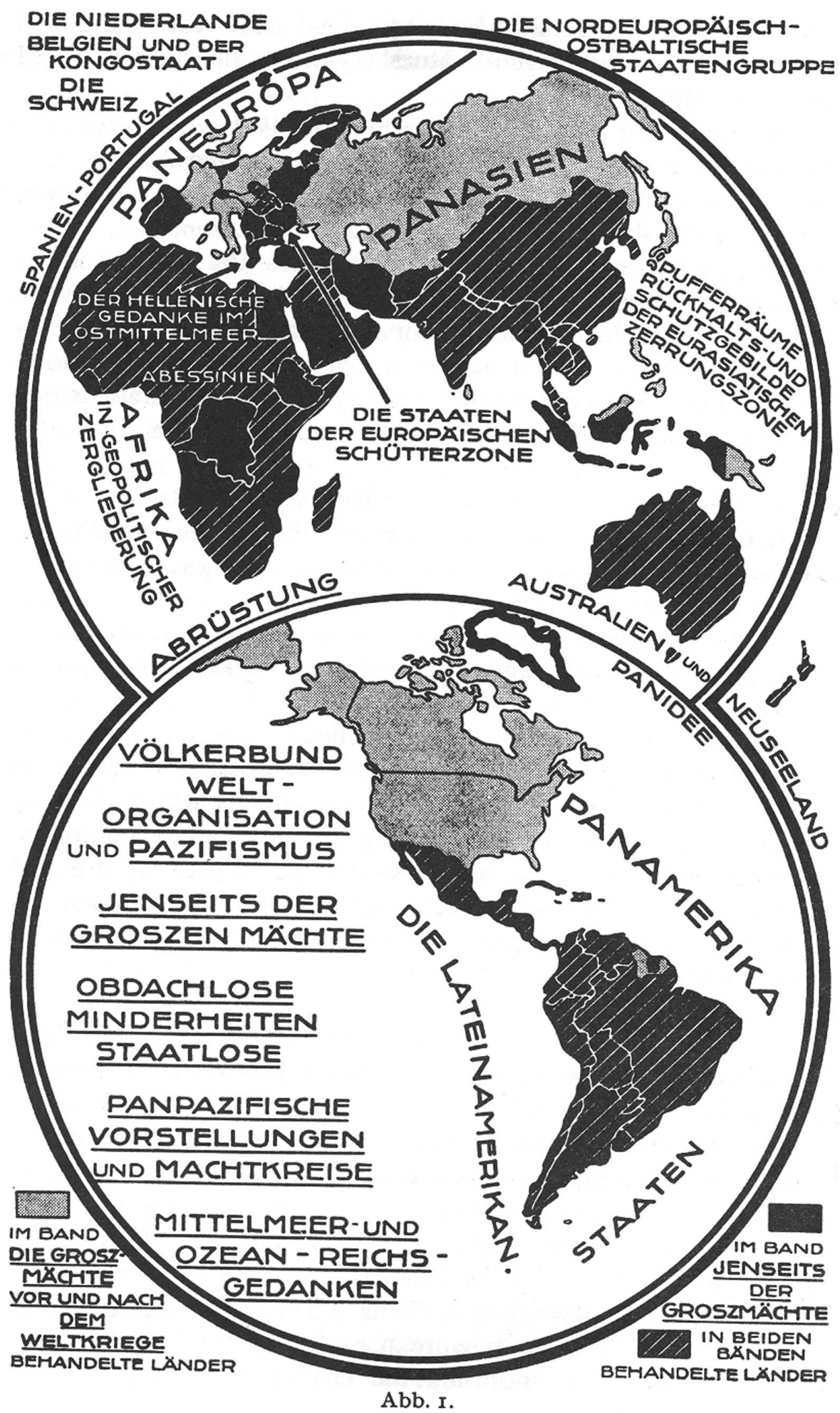


Se o modelo era plausível ou não na época em que foi formulado pela primeira vez é uma pergunta que somente pode ser respondida $a$ posteriori. O que se pode afirmar é que estava claro que se pretendia alterar todo o ordenamento do mundo na época e, apesar de se contar com a colaboração explícita do Japão, nunca se conseguiu o consentimento dos Estados Unidos. Ainda mais: o Reino Unido, a antiga potência hegemônica então em largo declínio, conseguiu provocar uma transição geopolítica em termos mais favoráveis para ela, assumindo os Estados Unidos, após o final da Segunda Guerra Mundial, claramente o papel que até então desempenhavam os britânicos. Em outras palavras, os nazis não foram capazes de estabelecer um consenso hegemônico-em termos gramscianos - acerca de seu modelo de mundo. As pan-regiões não entraram na agenda política daquele momento. Em suma, não conseguiram impor sua representação do espaço e suas opções políticas foram anuladas.

Obviamente, a América Latina incluía-se na denominada Pan-América, desempenhando o papel de região abastecedora de matérias-primas para a industrializada costa Leste dos Estados Unidos, ao mesmo tempo em que se constituía em mercado de consumo para seus produtos. Para Haushofer, a idéia pan-americana estava bastante desenvolvida graças à doutrina Monroe, especialmente no campo do direito internacional, "apesar da oposição entre o norte germano-americano e o sul iberoamericano" (1986, p.219), o que, em todo caso, não seria suficiente para dissolver a poderosa cola das pan-idéias.

Pode-se supor que essa é uma situação radicalmente diferente do modelo mackinderiano, mas, a meu ver, nos encontramos, basicamente, com o mesmo tipo de relações entre a América Latina e os Estados Unidos, que, desde então, já era a potência marítima: seja no modelo do cinturão exterior ou no da Pan-América, a América Latina sempre é representada como um apêndice subordinado da potência hegemônica.

\section{CENÁRIO DA CONTENÇÃO GLOBAL NA GEOPOLÍTICA IDEOLÓGICA DA GUERRA FRIA}

A geopolítica ideológica se caracterizou pelos

valores, mitos e slogans procedentes das experiências dos dois Estados vitoriosos, os Estados Unidos e a União Soviética, que definiriam e determinariam as condiçốes da imaginação geopolítica daquele período. Uma dessas potências, os Estados Unidos, demonstraria maior efetividade em conseguir uma aceitação mais ampla para seu 'modelo' de organizaçãoo político-econômica, mas seu êxito baseava-se fundamentalmente na presença ativa do outro como ponto de comparação e ameaça (Agnew, 2003 [2005, p.21]).

Nos modelos geopolíticos desse período, insiste-se mais nos espaços ocupados pelas duas superpotências que disputam o domínio do mundo, que nos efeitos de sua localização e em suas características ambientais.

\section{A estratégia da contenção}

George Kennan, um funcionário do governo estadunidense na União Soviética, ao final da Segunda Guerra Mundial, em seu famoso Telegrama Longo de Moscou, ou no artigo assinado como "Mr. X”, em Foreign Affairs de julho de 1947, sustentou que a União Soviética era um espaço totalmente diferente com o qual não se podia estabelecer nenhuma aliança definitiva. Como afirmava Agnew (2003), essa afirmação teve uma grande influência nas decisões políticas dos Estados Unidos em relação à Guerra Civil grega (1947) e à fundação da OTAN (1949). Aqueles que, durante a Segunda Guerra Mundial, tinham sido aliados convertiam-se, assim, em nucleadores de dois espaços fixos e imutáveis, que, em parte, nasceram dos Acordos de Yalta, mas que seriam conformados nos primeiros anos da Guerra Fria. É certo que a estratégia estadunidense de fixar os limites da área de influência soviética responde, em boa medida, às prescrições do modelo de Mackinder, com as modificações introduzidas por Spykman. ${ }^{7}$

"George Kennan pode não reconhecer a dívida, mas [seus trabalhos] direta ou indiretamente levam o carimbo da visão do mundo de Mackinder" (Gray, 1988, p.4). 
E essa relação parece ficar mais clara se levarmos em consideração que as áreas que Kennan afirmava como vitais para a segurança nacional dos Estados Unidos - as quais, sob nenhum pretexto, deviam cair em mãos contrárias - coincidem praticamente com o cinturão interior mackinderiano ou o anel continental de Spykman, mais as áreas acrescentadas do Japão, Filipinas e dos países de Sul-americanos do oriente para o norte (ver Gaddis, 1982). É certo também que essas últimas contribuições deixam claro que as argumentações de Kennan não são mackinderianas, mesmo que possam se aproximar em alguns aspectos.

O estabelecimento de um verdadeiro arco de alianças militares anti-soviéticas nas periferias euro-asiáticas (OTAN, CENTO, SEATO) responde à necessidade de impedir a expansão da União Soviética nessa área, pois poderia se apoderar de todo o mundo. Ela está orientada fundamentalmente por um projeto ideológico anticomunista, mais que por considerações acerca do eterno enfrentamento entre a potência continental e a potência marítima. Trata-se do desenvolvimento ampliado do conceito de contenção, primeiramente elaborado por Kennan, ao fazer referência ao embargo econômico e militar da União Soviética, pelo que advogava.

A contenção é um dos três conceitos geopolíticos que, segundo Agnew (2003), desempenharam um papel fundamental na naturalização das concepções do espaço e da política global próprias da Guerra Fria. Os outros dois conceitos seriam o do efeito dominó e o da estabilidade hegemônica.

A teoria do efeito dominó serviu para expandir o conceito de contenção para além dos confins euro-asiáticos. A idéia era simples e foi muito utilizada - com bastante efetividade, diga-se de passagem - por diversos membros do governo dos Estados Unidos:

quanto antes se eliminar qualquer ameaça potencial ao status quo global, onde quer que fosse, seria menos provável que se produzisse uma difusão ou um efeito contagioso que viesse a afetar no futuro aos Estados Unidos. Em uma versão mais sofisticada, a teoria do efeito dominó afirmava que a credibilidade dos interesses estadunidenses em regiões-chave, como a Euro- pa, seria prejudicada se não conseguissem proteger os Estados satélites situados nos cantos mais remotos do globo. Em tais circunstâncias, a resolução dos Estados Unidos de resistir a qualquer agressão seria colocada em dúvida, e o Grande Inimigo se sentiria encorajado (Agnew, 2003 [2005, p.132]).

O conceito de estabilidade hegemônica se desenvolveu de forma mais consistente na Guerra Fria, e aludia à necessidade de alguma potência impor certa ordem nas relações internacionais. Nesse caso a hegemonia estadunidense se apresentava como benevolente ou, ao menos, como um mal necessário.

A imagem de dois enormes blocos espaciais, que não deveriam ter variações internas significativas, converteu-se em elemento fundamental da imaginação geopolítica da Guerra Fria (Figura 4). A América Latina estava incorporada na área de influência dos Estados Unidos, uma parte, inclusive, como foi mencionado acima, integrava o anel de contenção do comunismo. Talvez a teoria do efeito dominó tenha sido a que serviu para legitimar e tornar compreensíveis numerosas intervenções estadunidenses na América Latina, sob a justificativa da necessária contenção do comunismo.

\section{A Geopolítica conservadora, herdeira de Mackinder}

Nos anos 1970, produz-se uma renovação das idéias geopolíticas que poderíamos denominar conservadora. Nessa renovação, destaca-se o papel de Henry Kissinger (ver, p. ex. Hepple, 1986), que reintroduz o termo, ainda que com um sentido um tanto genérico, aplicando-o aos aspectos globais das relações internacionais. Entretanto, talvez, os trabalhos de Gray sejam os mais representativos dessa corrente renovadora, que se proclama herdeira intelectual da Geopolítica tradicional, em especial de Mackinder, e de suas práticas ligadas à atividade militar dos Estados. A proposta de Gray é a de orientar a política exterior dos Estados Unidos com base no modelo descrito em Democratic Ideals and Reality: "A rivalidade soviético-americana é somente a última manifestação do antagonis- 
Figura 4 - O mundo da estratégia de contenção (1959)

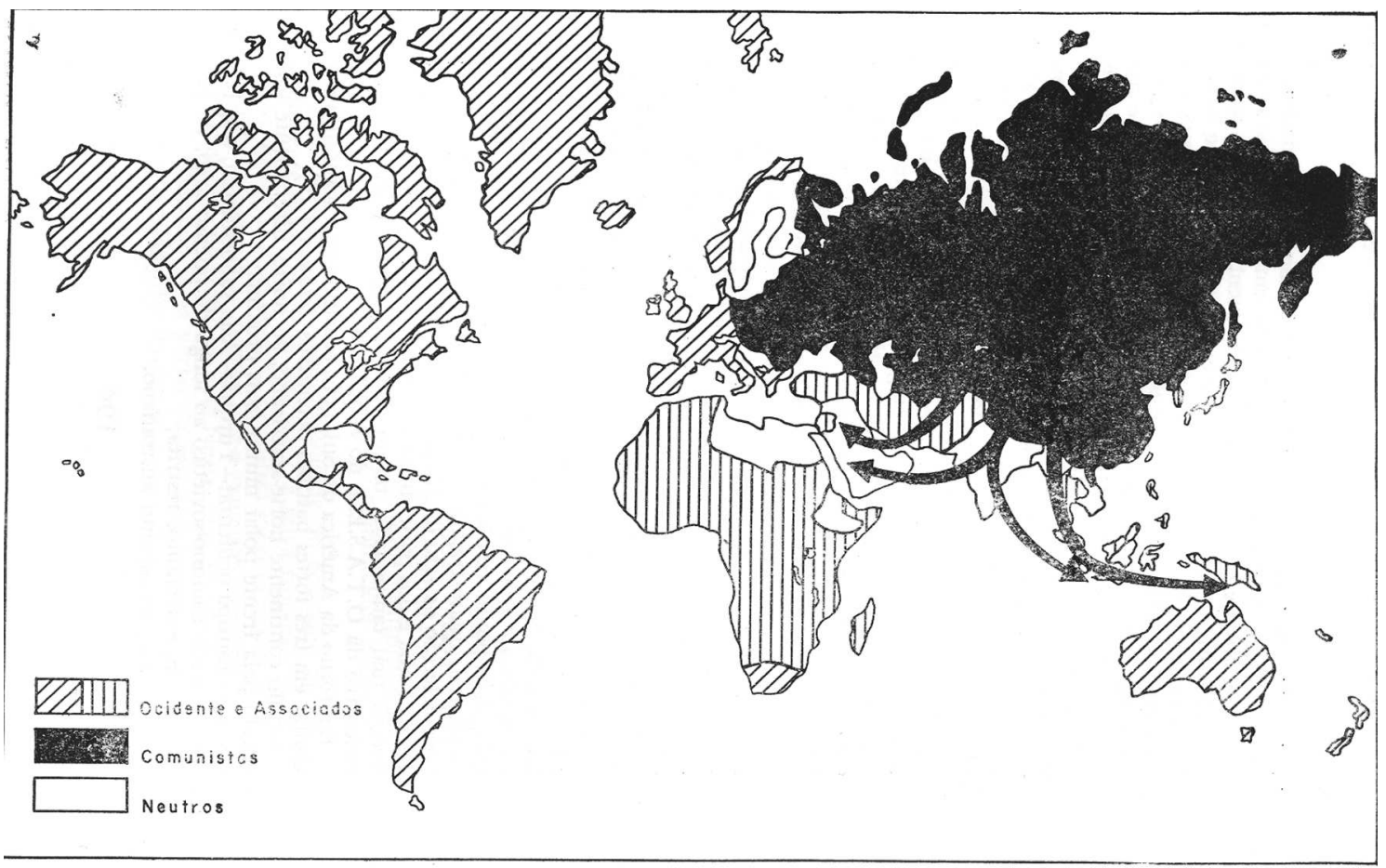

Fonte: Silva (1967, p.193)

mo entre a potência terrestre e a potência marítima sobre a qual Halford Mackinder escreveu” (Gray, 1988, p.194-195). E a obra de Spykman estabelece conexões entre os pais fundadores e essa Geopolítica conservadora renovada. Gray (1988), em particular, entende que a seqüência Mahan, Mackinder e

Spykman conforma as bases de uma concepção da Geopolítica superior a outras alternativas.

Partindo das idéias de Mackinder sobre a suposta superioridade geoestratégica da potência continental, com vistas a restabelecer o equilíbrio de forças e assegurar o êxito da estratégia da contenção durante a Guerra Fria com a União Soviética, torna-se necessário dotar-se de armas superiores (Gray, 1977). A decisão de desenvolver um arsenal nuclear que tornasse acreditável a dissuasão inaugura a corrida de armas nucleares entre as superpotências, já que a percepção soviética de sua situação de inferioridade estratégica, por não possuir armas nucleares, a conduz a desenvolver a bomba, e assim deflagra-se a espiral. No entanto, paradoxalmente, chega um momento em que a magnitude dos respectivos arsenais nucleares foi tanta, que a des- truição mútua era uma realidade. Com exceção de uma perspectiva suicida, a posse desses arsenais, então, já não supõe uma dissuasão definitiva.

Os advogados do velho dito de Si vis pacem para bellum sustentaram que a ausência de conflito aberto entre as superpotências, desde o fim da Segunda Guerra Mundial, se deve à adoção pelos Estados Unidos de uma estratégia de dissuasão. Sobre o processo aberto ao final dos anos 1980, que culminou com o fim da União Soviética, também estabelecia que ele só poderia ser mantido se continuassem desenvolvendo meios de contradissuasão, como a guerra das galáxias, dado que

um acordo geral - a diferença de um modus vivendi tático - nas relações soviético-americanas é estruturalmente impossível a não ser que se produzam mudanças fundamentais na natureza do Estado soviético, e talvez nem sequer neste momento", já que "a União Soviética é a potência terrestre [...], o império Grande Russo organizado por e para a maior satisfação dos patrióticos grandes russos, legitimados por uma ideologia transnacional que é inteiramente uma ferramenta de controle para a elite política governante (Gray, 1988, p.194-195, o destaque é nosso). 
Em suma, o problema não era somente o de uma oposição ideológica, já que, para os herdeiros de Mackinder, produzia-se uma oposição geográfica de caráter quase metafísico entre a União Soviética-Rússia e os Estados Unidos, que ia além das possíveis diferenças ideológicas conjunturais.

Mas o ponto principal que nos interessa assinalar é que Gray, nos anos 1970 e 1980, considerava que a União Soviética havia se estendido para além dos limites do anel continental da Eurásia. Nesse sentido, a contenção perimétrica stricto sensu já não tinha mais sentido, propondo então que se adotassem outras estratégias como a de contenção dinâmica ou a de forçaro retrocesso (rollback) (Gray, 1988). Essas políticas eram de aplicação especial do que Gray denomina avançadas do império soviético, que se estenderiam por todo o mundo. Na América Latina, considerava a Cuba e a Nicarágua como as principais "avançadas soviéticas".

A América Latina (e o resto do mundo) se converte, assim, no cenário de uma pugna ideológica em que qualquer avanço do império expansionista (obviamente somente da União Soviética) deveria ser freado pelos Estados Unidos. Desse modo, os projetos revolucionários cubanos ou nicaragüenses da época da Guerra Fria eram interpretados não como respostas (auto-produzidas) à situação da ditadura política e de extrema desigualdade social que existia nesses países, mas como vanguarda da penetração soviética. ${ }^{8} \mathrm{E}$, seguindo a lógica da teoria do efeito dominó, desenharam-se e impuseram-se políticas de isolamento e assédio para ambos os regimes, como, por exemplo, o embargo a Cuba ou o apoio à contra Nicarágua.

Desse modo, a América Latina se converteu, sobretudo na segunda metade da Guerra Fria, em cenário dos enfrentamentos entre as duas superpotências, que se realizavam através de segundos interpostos ou diretamente, no caso dos Estados Unidos. Tal enfrentamento gozou, até certo

\footnotetext{
${ }^{8}$ Os projetos da Cuba castrista ou da Nicarágua sandinista podiam seguir linhas similares aos da União Soviética, mas os regimes de ambos Estados não foram simplesmente títeres de Moscou. Essa é uma das manipulações favoritas desse tipo de autores realistas.
}

ponto, da cumplicidade da intelligentsia latinoamericana. Do mesmo modo que, no século XIX, as pugnas e conflitos entre liberais e conservadores respondiam, em boa medida, a interesses e projetos externos, socialistas de diferentes orientações e (neo)liberais unidos a (neo)conservadores reproduzem idéias e estratégias que têm sua origem fora da região. Não existe um projeto latinoamericano autônomo, que resista aos desígnios dos modelos geopolíticos globais.

\section{A AMÉRICA LATINANOS MODELOS GEOPOLÍTICOS DO PÓS-GUERRA FRIA}

A queda do Muro de Berlim, que simbolizou o fim do socialismo real, implicou o término da era da geopolítica ideológica e a definição de uma nova era sobre premissas diferentes, ainda que nem sempre inteiramente novas. De fato, autores de grande impacto midiático e político nos anos 1990, como Zbigniew Brzezinski, argumentam nos mesmos termos mackinderianos, embora ampliem a ênfase, do modelo no âmbito regional, o cinturão interior, a um global, todo o continente euro-asiático:

Os Estados Unidos, uma potência não euro-asiática, desfrutam atualmente da primazia internacional, e seu poder se desdobra diretamente sobre três das periferias do continente euro-asiático, a partir das quais exerce uma poderosa influência sobre os Estados que ocupam o hinterland euro-asiático. Mas, no campo de jogo mais importante do planeta, Eurásia, é onde poderia surgir, em algum momento, um rival potencial dos Estados Unidos (1997 [1998, p.47-48]).

Isso nos faz refletir sobre o fato de que, embora as transformações do discurso geopolítico dominante sejam profundas e evidentes, há autores que continuam empenhados em mostrar as supostas forças telúricas subjacentes à política mundial.

Mas não vou ocupar-me aqui dessas lembranças, já que não contribuem para elucidar nenhuma visão radicalmente nova sobre o papel da América Latina no mundo. Pelo contrário tratarei de dois novos modelos: o de Samuel Huntington e o de Thomas P. Barnett. 


\section{Huntington e seu mundo de civilizações em pe- rigo de colisão}

Samuel Huntington $(1993 ; 1996)$ publicou dois trabalhos nos anos 1990 sobre o pretendido choque de civilizações, que tiveram (e em alguns círculos, ainda têm) grande impacto sobre a forma de pensar o mundo. Em 1993, publicou um artigo com o título de The clash of Civilizations?, no qual estabelece que, após o fim de uma confrontação global baseada nas ideologias, haviam ressurgido linhas de fratura mais profundas e antigas, que têm sua origem supostamente nas civilizações, baseadas em identidades culturais mais poderosas que as identidades nacionais: "No mundo da Pós-guerra Fria, as distinções mais importantes entre os povos não são ideológicas, políticas nem econômicas; são culturais" (Huntington, 1996 [1997, p.21]). Assim os Estados-nação se agrupariam dentro de unidades maiores, as civilizações (Figura 5), que regeriam as relações internacionais e a política global.

O autor identifica nove civilizações: a Sínica ou Confuciana, a Japonesa, a Indiana, a Islâmica, a Ortodoxa, a Ocidental, a Latino-americana e a Africana (Huntington, 1996). Essas civilizações são definidas, fundamentalmente, por seus traços culturais, em particular pela religião. E é bom notar que essa define, grosso modo, as cinco primeiras civilizações da lista, enquanto que as duas últimas, as mais frágeis, carecem de uma identificação religiosa particular. Dentro dessa lógica, as possibilidades de conflito se associam à fricção entre civilizações, embora isso não queira dizer que não existam conflitos intra-civilizações, mas sim que os que podem chegar a ser os mais graves são de natureza inter-civilizacionais.

Vários críticos afirmaram acertadamente que o esforço de Huntington, dentro de um espírito da mais pura realpolitik, orienta-se para a reconstituição do Outro da política exterior estadunidense, depois da queda do muro de Berlim, de tal forma que as coletividades baseadas em raízes culturais substituiriam os blocos de caráter ideológicos da Guerra Fria. Com isso, preten-

Figura 5 - O mundo segundo Huntington (1996)

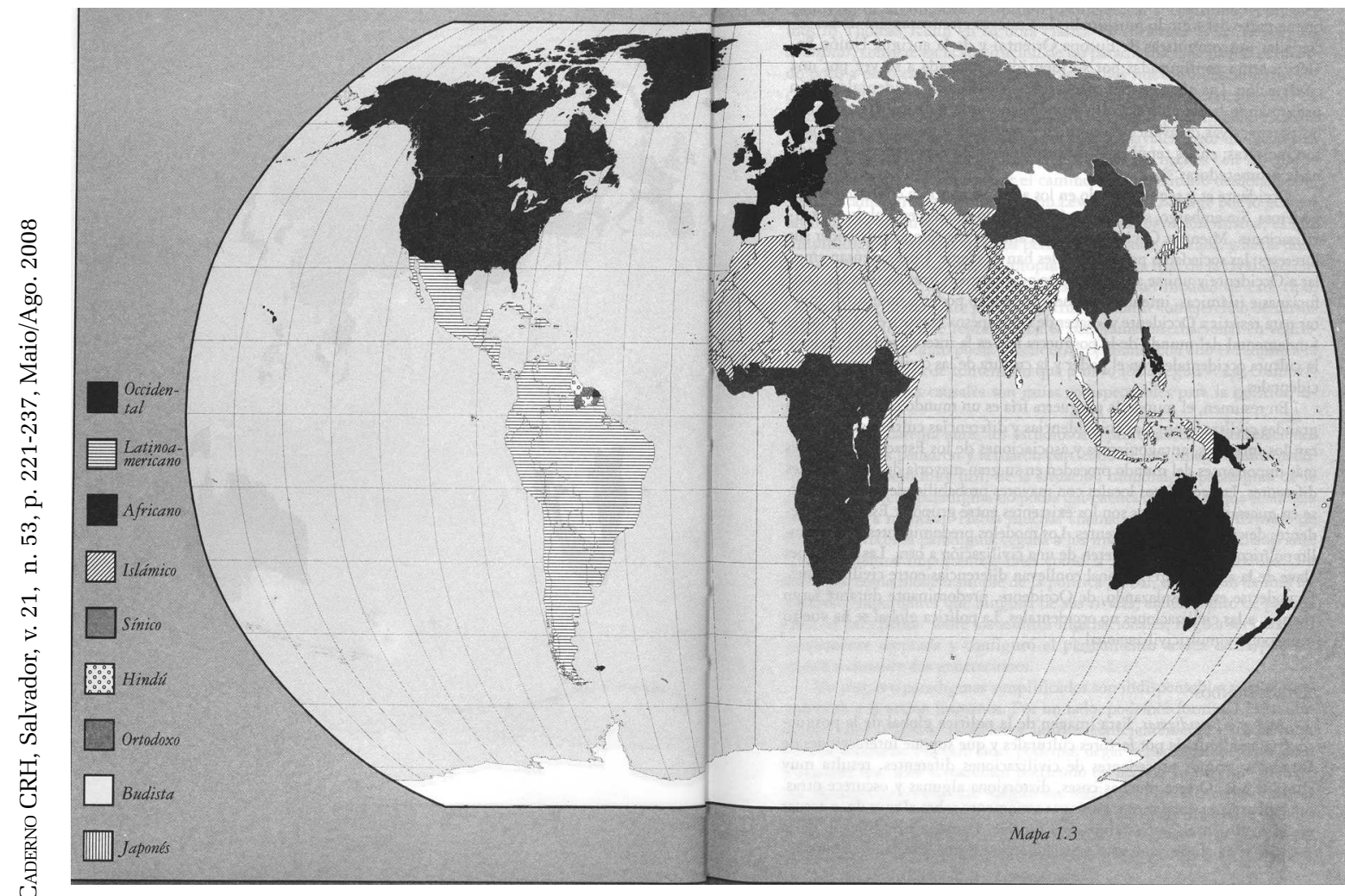

Fonte: Huntington (1996 [1997, p. 28-29) 
de-se definir as linhas divisórias entre civilizações como aquelas centrais do conflito na política global. Este fato viria garantido pela graduação do antagonismo que Huntington estabelece entre a civilização Ocidental e as demais, sendo a Islâmica a mais perigosa, seguida da Ortodoxa, a Sínica e a Japonesa, ficando o resto em uma situação de aliança mais ou menos estreita.

Mas, no que nos interessa, existem dois elementos importantes para o fato de a América Latina ter sido definida como uma região geopolítica (uma civilização, em termos de Huntington) independente. Um deles resulta de dúvidas do autor quanto à real existência de uma civilização latino-americana. No seu primeiro artigo (Huntington, 1993), ele se pergunta se a América Latina é uma civilização independente ou não, deixando nos leitores a dúvida. Mas, no seu livro posterior, embora permaneça na incerteza, assume uma determinação:

A América Latina poderia ser considerada, ou uma sub-civilização dentro da civilização ocidental, ou uma civilização à parte, intimamente relacionada com Ocidente e dividida quanto ao seu domínio com o mesmo. Para uma análise centrada nas conseqüências políticas internacionais das civilizações [...] a segunda opção é a mais adequada e útil (Huntington, 1996 [1997, p.52].

O segundo elemento importante resulta das bases fundamentais de diferenciação que a distinguem da ocidental (européia e norte-americana), que seriam a incorporação de civilizações indígenas americanas, a religião católica e "uma cultura corporativista e autoritária que a Europa teve em menor grau e a América do Norte não teve em absoluto" (Huntington, 1996 [1997, p.52]).

Então, diferentemente dos modelos anteriores, para Huntington, a América Latina é apresentada de forma independente, já não se constitui uma brevíssima alusão perdida entre as terras do cinturão exterior mackinderiano, nem um território ocidental onde se poderiam estabelecer "avanços comunistas"; é uma região diferenciada do Ocidente, aliada, sim, mas independente. E são também significativas as razões da diferenciação dadas por Huntington, já que a religião católica ou a cultura corporativa não são exclusivas da América Latinana Europa, e, em particular, na Europa meridional esses traços poderiam ser também diferenciadores -, mas a presença significativa de civilizações indígenas certamente seria seu traço fortemente distintivo, tanto que caberia a pergunta se essa é a chave para diferenciar a América Latina do ocidente, mas esta se dilui com a menção a dois outros traços. Sobre esse aspecto voltaremos no final.

\section{Thomas P. Barnett: o novo mapa do Pentágono}

Quase um século depois da obra de Mackinder, Thomas P. Barnett (2003) quebra o ciclo argumental do inglês: já não há que resolver problemas que encontramos num mundo fechado, pós-colombino, mas, ao contrário, o perigo é a desconexão. Num primeiro artigo escrito na conservadora revista Esquire, ele condensa os argumentos que mais tarde apresentará em forma de livro (2004). Barnett se afasta decisivamente do modelo mackinderiano, embora muitas de suas zonas de perigo continuem coincidindo com as do cinturão interior.

Seu argumento principal é que a globalização, por mais problemas que possa ter, conduz a governos estáveis e a políticas exteriores dos Estados previsíveis e pacíficas. Nesse sentido, os problemas no mundo surgem exatamente naqueles Estados que tentam resistir à globalização. Desse modo, em seu modelo (Figura 6), o que ele denomina "centro funcional" (Functioning Core) seria caracterizado por sua integração graças à conectividade de redes, às transações financeiras, aos fluxos de informações midiáticas e à segurança coletiva, enquanto a "brecha não integrada" (NonIntegrating Gap) careceria, em diferentes graus, dessas características, conduzindo estas regiões a "regimes politicamente repressivos, à expansão massiva da pobreza e da enfermidade, assassinatos massivos rotineiros e - o mais importante - a conflitos crônicos que envolvem a geração seguinte de terroristas" (2003).

Se observarmos o mapa da "brecha não integrada", podemos ver que nela está incluído o Caribe, a América Central e a maior parte da Amé- 
rica Andina - é significativa a ausência do Chile. Como era de se esperar, em seguida, na lista de problemas reais anexada por Barnett (2003), estão incluídos países como Haiti e Colômbia, que se ajustam bem ao seu argumento. E, surpreendentemente, inclui-se também a Argentina e Brasil, que sequer compõem a dita "brecha não integrada". Quais são os motivos que levam a Barnett a este juízo? Entre os principias argumentos que Barnett utiliza está, nem mais nem menos, o de que ambos os países tentam resistir à ALCA, que o Brasil não cuida da Amazônia e permite que se continue produzindo um dano ecológico incalculável nessa área ingovernável.

Talvez esses argumentos sobre os paíseschave do MERCOSUL lancem mais luzes sobre a lógica do modelo geopolítico de Barnett do que todo seu palavreado sobre a "desconexão da globalização". O perigo desses países está em que, eventualmente, podem chegar a serem autônomos em relação ao projeto hegemônico. Por isso, países como o México, cujos governos se curvam aos projetos hegemônicos são tão importantes, são os Estados junção (seam states), que são chaves nas estratégias de redução da brecha.

\section{CONCLUSÕES}

A Geopolítica é uma disciplina nascida na Europa, como tantas outras, mas que tem um viés eurocêntrico ainda maior que outras. Os autores anglo-saxões e alemães que desenharam a representação do espaço mundial dominante ao longo do século XX pensaram a América Latina como uma região de importância marginal no mundo, que sempre estava vinculada à área de influência da potência marítima (Mackinder), à pan-região centrada nos Estados Unidos (Haushofer), ou ao mundo livre (Kennan). Em termos gerais, era considerada distante do cenário principal do conflito central do mundo, entre a potência marítima e a potência terrestre, primeiramente, ou entre o mundo livre e o mundo comunista, depois, e que se desenvolvia fundamentalmente na zona de conta- to (ou de ruptura) entre as potências mundiais (Europa Oriental Oriente Médio, Sudeste Asiático, Ásia Oriental).

Mas não se trata somente de uma marginalização originada nas áreas centrais do sistema mundial e concebida por seus intelectuais; pelo contrário, sem a aceitação e o acatamento de boa parte da intelligentsia latino-americana, não se produziria tão facilmente esta relegação. Um bom exemplo nos proporciona Golbery do Couto e Silva, na ocasião um dos poucos intelectuais latinoamericanos que elaborou um modelo geopolítico para o Brasil. Sua obra Geopolítica do Brasil glosa extensamente as teorias de Mackinder e Spykman, afirmando seu acerto, especialmente no contexto da luta anticomunista da Guerra Fria. Introduz somente um "porém": o Ocidente, e em particular Estados Unidos, não levam em conta a relevância da América Central e da América do Sul na luta de contenção do comunismo, em termos de apoio diplomático, fornecimento de materiais estratégicos, proteção do tráfico marítimo ou potencial demográfico para participar em campanhas militares." (Silva, 1967). Mas, é importante ressaltar o caráter subordinado de sua formulação: o Ocidente necessita do Brasil e da América Latina, mas

$$
\begin{aligned}
& \text { por outro lado, o Brasil depende essencialmente } \\
& \text { - e quanto! - do restante do Ocidente e, em par- } \\
& \text { ticular dos E.U.A., para o seu comércio, o seu } \\
& \text { desenvolvimento econômico, o seu progresso téc- } \\
& \text { nico e cultural, até para a sua própria segurança } \\
& \text { (1967, p.254). }
\end{aligned}
$$

Contudo, desde o fim da Guerra Fria e o advento de uma nova ordem geopolítica, os modelos geopolíticos que tentam explicá-lo, apresentam a América Latina como uma região muito mais autônoma que os anteriores. Ecertamente continuam sendo principalmente os autores europeus e estadunidenses aqueles que continuam elaborando os modelos de maior influência. Os exemplos de Huntington ou Barnett são bastante claros:O queaconteceu?Que transformações se produziram então?

Evidentemente não há um fator único, mas, indubitavelmente, tem a ver com a aparição de projetos políticos - e epistêmicos - autônomos na América Latina, que talvez conduzam a apresentá- 


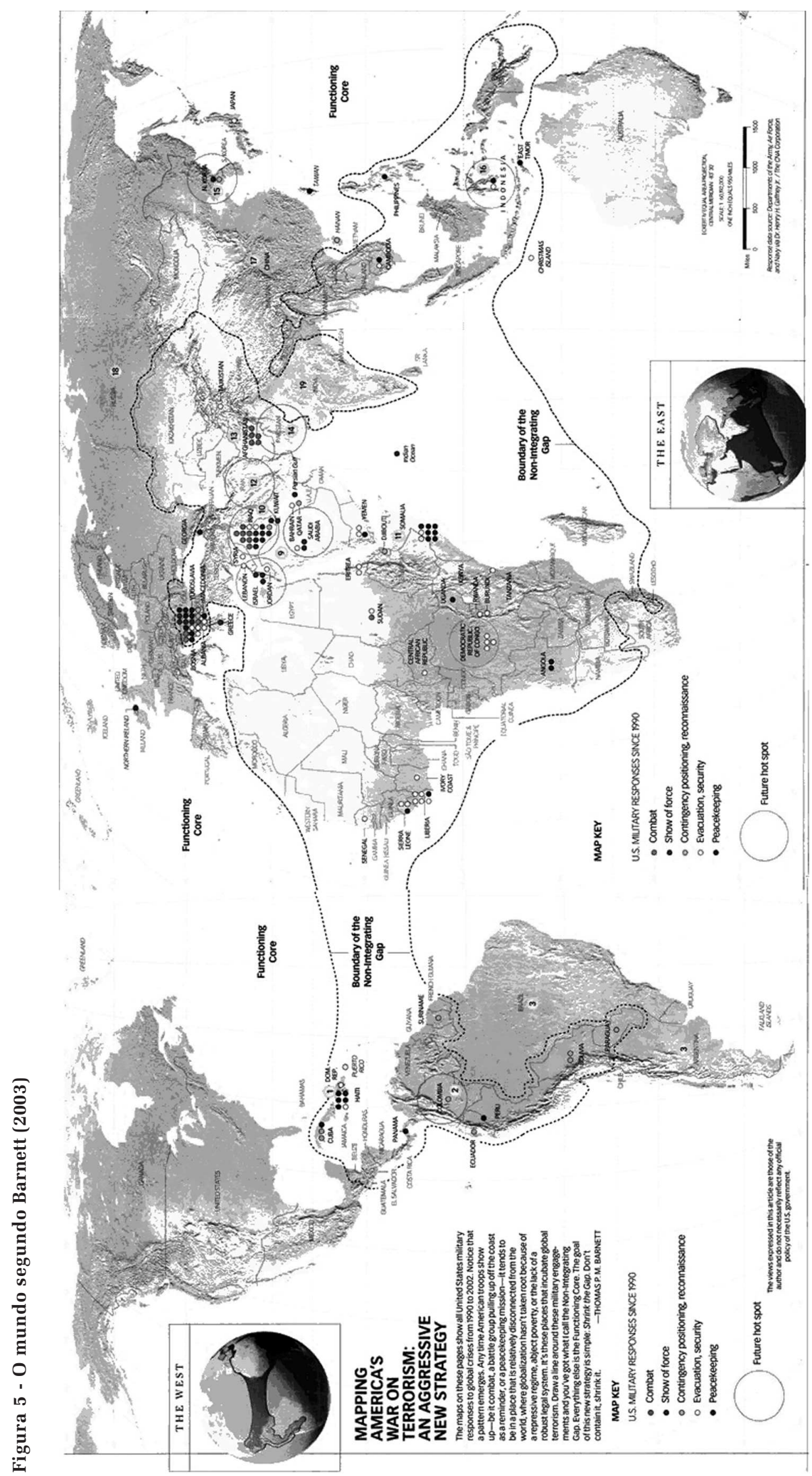


la como uma região autônoma. Eé quase pela primeira vez que, desde a independência formal dos Estados latino-americanos, nos encontramos com projetos políticos relativamente independentes das potências européias e da potência hegemônica. São bons exemplos disso o acesso à presidência de um integrante de um dos grupos excluídos nos processos de independência há dois séculos, Evo Morales, na Bolívia, mas também o projeto boliviano de construção da unidade latino-americana, do presidente Chávez na Venezuela, ou a condução de uma política exterior autônoma que procura desenhar uma nova geografia mundial do $\mathrm{Co}$ mércio do governo Lula da Silva, no Brasil.

E a esses projetos políticos somam-se projetos intelectuais autônomos, como o projeto modernidade-colonialidade, no qual estão embarcados Aníbal Quijano, Enrique Dussel, Walter Mignolo, Santiago Castro-Gómez, Arturo Escobar, Catherine Walsh, Ramón Grosfoguel e Nelson Maldonado-Torres, entre outros. Projetos de indígenas, mestiços, afro-descendentes, latinos nos Estados Unidos, que resistem ao império (Slater, 2008) do conhecimento e tentam construí-lo a partir de outro lócus e com outras genealogias. É certo que "o pensamento des-colonial emergiu na própria fundação da modernidade/colonialidade, como sua contrapartida. E isso ocorreu nas Américas, no pensamento indígena e no pensamento afrocaribenho.” (Mignolo, 2008, p.181). Mas não é menos certo que, desde que se iniciou a colonização, há mais de cinco séculos nunca como até agora se haviam desenvolvido projetos (geo)políticos e (geo)epistêmicos autônomos na América Latina.

(Tradução de Consuelo Brito de Freitas)

(Recebido para publicação em junho de 2008) (Aceito em agosto de 2008)

\section{REFERÊNCIAS}

AGNEW, John. Geopolitics: Re-visioning World Politics, 2.ed., Londres: Routledge, 2003 [Trad. ao castelhano de LOIS BARRIO, M. D.. Geopolítica: Una re-visión de la política mundial. Madrid: Trama Editorial, 2005]
; CORBRIDGE, Stuart. Mastering Space: Hegemony, Territory and International Political Economy, Londres: Routledge, 1995.

BARNETT, Thomas P. The Pentagon's New Map: It explains why we're going to war, and why we'll keep going to war. Esquire: magazine for men, Chicago-USA, mar., 2003.

. The Pentagon's New Map: War and Peace in the Twenty-First Century. Nova York: Putnam, 2004.

BRZEZINSKI, Zbigniew. The Grand Chessboard. American Primacy and its Geostrategic Imperatives. Nova York: Basic Books, 1997 [Trad. ao castelhano El tablero mundial. La supremacía estadounidense y sus imperativos geoestratégicos. Barcelona: Paidós, 1998].

GADDIS, John L. Strategies of Containment. Oxford: Oxford University Press, 1982.

GRAY, Colin S. The Geopolitics of the Nuclear Era: Heartland, Rimlands, and Technological Revolution. Nova York: Crane, Russak \& Co, 1977.

The Geopolitics of Superpower. Lexington: University Press of Kentucky, 1988.

HAUSHOFER, Karl. Geopolitik der Panideen. Berlim: Zentral Verlag, 1931.

De la géopolitique. Paris: Fayard, 1986 [Trad. ao francềs de seleção de textos].

HEPPLE, Leslie W. The revival of geopolitics. Political Geography Quarterly, Londres, Elsevier, n.5, p.21-36, 1986.

HUNTINGTON, Samuel P. The clash of civilizations? Foreign Affairs, Nova York- US, Council on Foreign Relations, n.72, p. 22-49, 1993.

The Clash of Civilizations and the Remaking of World Order. Nova York: Simon \& Schuster, 1996. [Trad. ao castelhano de TOSAUS, J. P. El choque de civilizaciones y la reconfiguración del orden mundial. Barcelona: Ed. Paidós, 1997].

KJELLÉN, Rudolf. Staten som Lifsform. Estocolmo: Hugo Gebers Förlag, 1916. [Trad. ao alemão de LANGFELDT, M. Der Staat als Lebensform. Leipzig: S. Hirzel, 1917].

MACKINDER, Halford T. "The geographical pivot of history”, Geographical Journal, n.23, p.421-437, 1904 [Trad. ao castelhano em: RATTENBACH, A. B. (Comp.): Antología Geopolítica. Buenos Aires: Pleamar, p. 65-81, 1975].

. Democratic Ideals and Reality: A Study in the Politics of Reconstruction. Londres: Constable, 1919 ["Defence Classic Edition”, Washington D.C.: National Defense University Press, 1996].

MIGNOLO, Walter. The Idea of Latin America, Oxford, Blackwell, 2005 [Trad. ao castelhano La idea de América Latina. La herida colonial y la opción decolonial. Barcelona: Gedisa, 2007].

La opción des-colonial: desprendimiento y apertura. Un manifiesto y un caso. Em: CAIRO, H.; apertura. Un manifiesto y un caso. Em: CAIRO, H.;
MIGNOLO, W. (Eds.) Las vertientes americanas del pensamiento y el proyecto des-colonial. Madrid: Trama Editorial/GECAL, p.177-210, 2008.

O'LOUGHLIN, John; VAN DER WUSTEN, Herman. "Political Geography of Panregions", Geographical Review, Nova York, American Geographical Society, v.80, n.1, p. 1-20, 1990.

PARKER, Geoffrey. Western Geopolitical Thought in the Twentieth Century. Londres: Croom Helm, 1985.

SAXE FERNÁNDEZ, John. La doctrina de las Áreas Económicas Amplias: su relevancia para México. Em: DELGADO, J.; VILLAREAL, D. R. (Coords.): Cambios territoriales en México. México: Universidad Autónoma Metropolitana Unidad Xochimilco, p. 23-41, 1991. 
SILVA, Golbery do Couto. Geopolítica do Brasil. Rio de Janeiro: José Olympio Editora, 1967.

SLATER, David. Geopolitics and the Post-colonial. Rethinking North-South Relations. Oxford: Blackwell, 2004.

Re-pensando la geopolítica del conocimiento: reto a las visiones imperiales. Em: CAIRO, H.; MIGNOLO, W. (Eds.) Las vertientes americanas del pensamiento y el proyecto des-colonial. Madrid: Trama Editorial/GECAL, p.155-175, 2008

SPYKMAN, Nicholas J. Geography and foreign policy, I. American Political Science Review, Baltimore, MD-USA, n.32, p.28-50, 1938.

Geography and foreign policy, II. American Political Science Review, Baltimore, MD-USA, n.32, p. 213-236, 1938.

\section{LATINAMERICA IN MODERN GEOPOLITICAL MODELS: from margination to the concern for her autonomy}

\section{Heriberto Cairo}

This paper tries to understand the transformations in the ways of insertion of Latin America in the context of geopolitical eras, trying to show their causes and, above all, their consequences, in the context of the new contemporary geopolitics in which the region moves from a passive or marginal position to assume her own outlines of autonomy, sometimes marked as danger areas. The analysis surpasses the simple position of the region in Western geopolitics, and is based on an exercise of a geopolitics of the knowledge. Thus, the author rescues the main contributions of the literature on processes of continuities of geopolitical orders, permeated by mutations, identifying the successive geopolitical eras of John Agnew that grosso modo are correlated with the existing geopolitical orders: the naturalizer geopolitics, from the beginnings of the XX century; the post-Second World War era, of the ideological geopolitics; and the formation of a new geopolitical era with the end of the Cold War. In this latter Latin America is highlighted with her own outlines, sometimes marked as danger areas.

Keywords: Latin America, modern geopolitics, knowledge geopolitics, representation of space, hegemony.
America's strategy in world politics. Nova York: Harcourt, Brace \& World, 1942.

The geography of the peace. Nova York: Harcourt, $\overline{\text { Brace }}$ \& World, 1944

TAYLOR, Peter J.; FLINT, Colin. Political Geography: Worldeconomy, Nation-state and Locality. Londres: Wiley, 2000 [Trad. ao castelhano de DESPUJOL, A.; CAIRO, H. Geografía política: Economía-mundo, Estado-nación y localidad. 2.ed. Madrid: Trama Editorial, 2002].

WEBER, Alfred. Alfred Weber's theory of the location of industries. 2.ed. Chicago: University of Chigago Press, 1957. [Trad ao inglês com introdução e notas de FRIEDRICH, C. J. Chicago: University of Chicago Press, ed. original, 1929]. Disponível em: www.csiss.org/classics/ content $/ 51$

\section{L'AMÉRIQUE LATINE DANS LES MODĖLES GÉOPOLITIQUES MODERNES: de la mise en marge à la préoccupation de son autonomie}

\section{Heriberto Cairo}

Dans cet article, il s'agit de comprendre comment les manières d'insérer l'Amérique Latine dans le contexte des ères géopolitiques se sont transformées. Nous essayons d'expliciter les causes et surtout les conséquences de ces transformations dans le contexte de la nouvelle géopolitique contemporaine où la région passe d'une position marginale ou passive pour assumer des contours propres d'autonomie, considérés parfois comme des zones dangereuses. L'analyse dépasse les limites de la région géopolitique occidentale et se base sur l'exercice d'une géopolitique de la connaissance. Pour cela, l'auteur récupère les principales contributions de la littérature concernant les processus de continuités des ordres géopolitiques, imprégnés de mutations, en identifiant les ères géopolitiques successives de John Agnew qui a grosso modo ont un rapport avec les ordres géopolitiques existants: la géopolitique naturalisatrice du début du $20^{\mathrm{e}}$ siècle; l'époque de l'après Deuxième Guerre Mondiale, de la géopolitique idéologique; et la formation d'une nouvelle ère géopolitique avec la fin de la Guerre Froide. Dans cette dernière, l'Amérique Latine commence à s'affirmer de manière propre, parfois marquée comme une zone dangereuse.

Mots-CLés: Amérique Latine, géopolitique moderne, géopolitique de la connaissance, representation de l'espace, hégémonie. 